\title{
Academic | Practice Partnership- Developing Responsive Architecture
}

DALE CLIFFORD

California Polytechnic State University
The Bio_Logic Design Group develops adaptive building technologies derived from emerging materials and biological principles. The group was formed to develop responsive architectural systems that bridge art, architecture, technology and engineering, and is housed in the College of Architecture and Environmental Design at Cal Poly.

\section{ABSTRACT}

Academic entities have the ability to assemble resources and form 'local labs' able to creatively address complex technical problems. This paper describes academic partnerships with professional practice that offer responsive materials design expertise not available in many architectural firms. The following projects are funded by grants, gifts, and consultation mechanisms with architectural firms during the Request for Qualifications (RFQ) and the Request for Proposals (RFP) phase in competitive design solicitations. The RFQ and the RFP mechanisms are high-value low-risk means for architectural firms to add research and development capabilities to their project team. Example are given of two collaborative projects that have brought practice-based research to the architectural office and brought practical experience to students.

\section{DESIGN PARTNERSHIP}

Successful collaboration between academia and practice requires that each partner add value to the other. The medical and engineering fields have long depended on universities to advance basic research that is risky, expensive and lengthily, and when outcomes are not immediately applicable to commercialization. The fields of architecture and design are relative newcomers to academic | practice partnerships, though schools of architecture have historically relied on the transfer of knowledge from practitioners to students. Advancements in material development, manufacturing technology and digital media have altered the way architecture is conceived and constructed, and the pace of this change has accelerated academic | private partnership. Many architectural firms by necessity become specialized to focus human and monetary resources. Academia, in contrast, takes a more generalized stance, as the university derives its identity form diversity. These differences can form the basis of productive partnerships.

Productive academic | practice collaboration is built upon trust and the shared interest to support a climate of innovation. It is becoming more common for universities and professional practice to form alliances that advance both the state of design research 


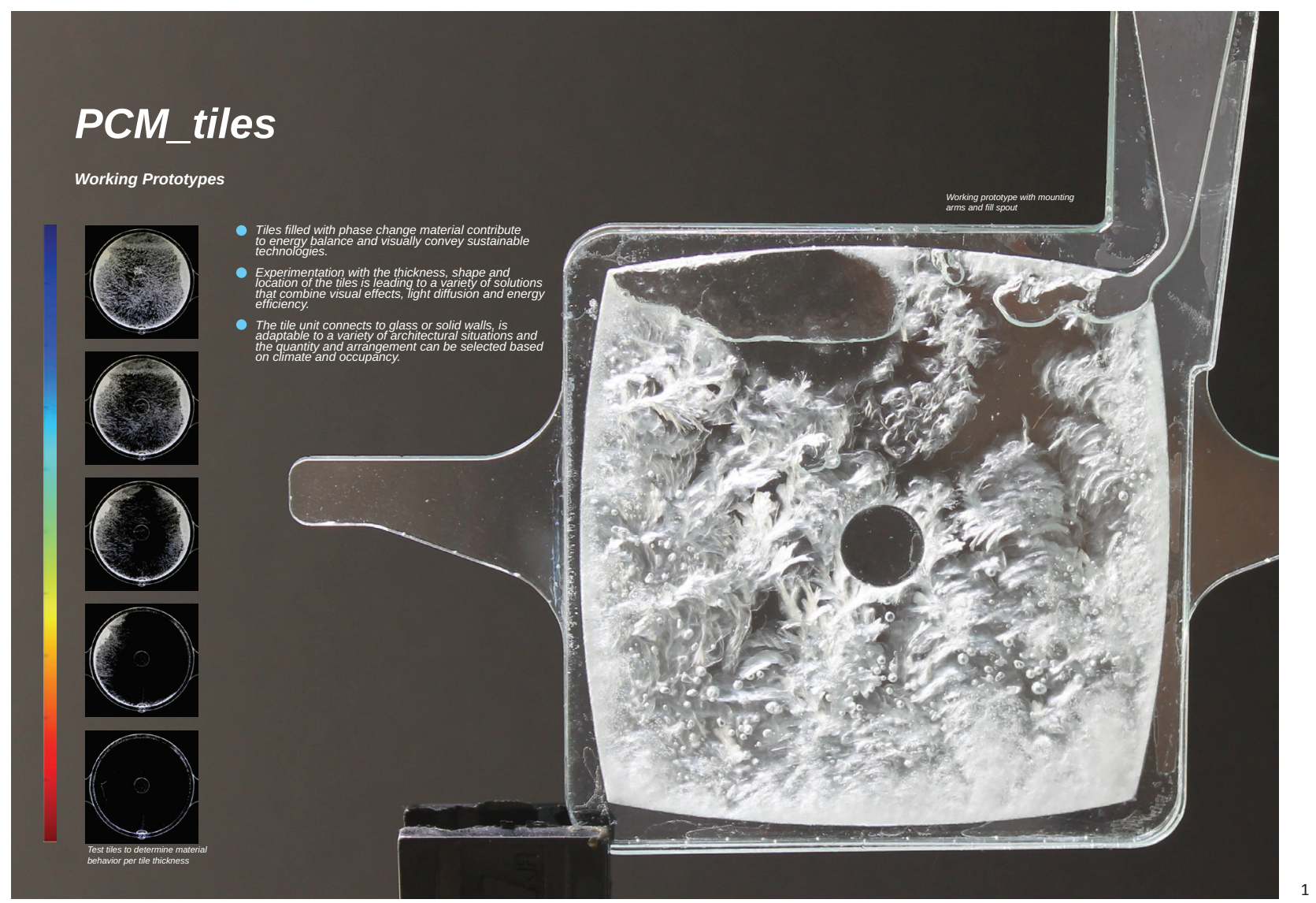

and the ability of practice to more effectively handle complex design problems. Design research, as used in this paper, is defined as the advancement of design methods to produce a preferred state. Complex design problems are defined as problems that are outside the expertise of design firms and their general consultants. Responsive material research and application, technology that is being transferred from the medical, automotive and aeronautical industries, fit this category. Responsive materials change their physical properties in response to external stimuli and have the potential to make the built environment more responsive to climatic fluctuation. Responsive materials exhibit a property change in response to a stimulus and are reversible. The benefits of a more responsive architecture are reduced energy consumption and the psychological effects of human awareness of environmental variation. The following projects describe an effort to make architecture more responsive to environmental fluctuation and to communicate this response to building occupants.

\section{PROJECT EXAMPLE 1: FRICK PARK ENVIRONMENTAL CENTER}

The Bio_Logic Design Group partnered with Bohlin Cywinski Jackson Architects (BCJ) in the RFQ and RFP stages of an international competitive project for the new Frick Park Environmental Center, Pittsburgh, PA. The project was directed by BCJ with the Bio_Logic Design Group contributing expertise in responsive building materials and as a creative engine to develop the visualization and interactive potential of sustainable technologies. An initial qualifications statement was prepared which included team members' affiliations and expertise. The team was successful and short-listed for the RFP phase. A number of preproject and conceptual design meetings were help prior to the RFP presentation to client to outline the collaborative process.

Figure 1: PCM filled glass tile designed for the visualization of sustainable technology (Frick Environmental Center). 
Site: Frick Park, Pittsburgh, PA: Frick Park is 644 acre park that has a sordid industrial history as it was a dumping ground for waste from Pittsburgh's steel mills. From $1920-$ 1972 the topography within the park was transformed; it was constructed from repeated dumping of slag, a by-product of iron ore smelting. The main slag pile covers 238 acres and reaches more than 20 stories high, contributing to sever biotic impoverishment ${ }^{1}$ of the area. Significant remediation is underway. This is the context for the new Frick Park Environmental Center. The mission of the Frick Environmental Center is educational and will bring diverse population groups in closer contact with nature through hands-on environmental activities. The Center will serve as a living laboratory for environmental design and educational practice as the building itself is intended to demonstrate sustainable principles to building occupants.

\section{PROJECT BACKGROUND}

The Frick project summarizes a collaborative effort between architect, consulting engineering firm and academic researchers to meet the energy petal of the Living Building Challenge for the Frick Park Environmental Center in Pittsburgh, PA. The team performed physical experiments and digital simulations to determine the ability of an emerging class of organic change materials (PCMs) to contribute to temperature balance and lower reliance on mechanical conditioning in a heating dominated climate, while contributing to the Center's educational mission to convey sustainable principles to the public. The work is also contributing to meeting LEED Platinum certification standards.

In response to the education requirements of Living Building Challenge, the design team (Bio_Logic Design Group, BCJ Architects, and TriPyramid) has designed a demonstration project in the main public gallery to showcase phase change material thermal storage devices. The teams' intent is to address the necessity to lower energy consumption by increasing the energy storage capabilities of the building envelope. Our approach is to use low-tech solid-state phase change material tiles for this purpose. PCM is also integrated into the building wall cavity, and helps to modulate internal temperature swings, lower reliance on building mechanical conditioning and met the energy petal of the LBC. The visual and tactile display in the gallery demonstrates the thermal storage capacity of PCM (Figures 1-3) and showcases the visual aspects of sustainable technology to visitors.

After the project was awarded through the RFP process, a contract was drawn between architect and consulting entity (Bio_Logic Design Group). Monies were then channeled from the consulting entity to the university in the form of a gift. The gift mechanism is similar to a grant, except that under the legal guidelines of a gift, the university extracts far less overhead, enabling a higher portion of monies to go directly to the academic project team. Figure 2: Experiment to quantify light transmission This method is currently under scrutiny, as university overhead, though it varies between and thermal storage capacity.

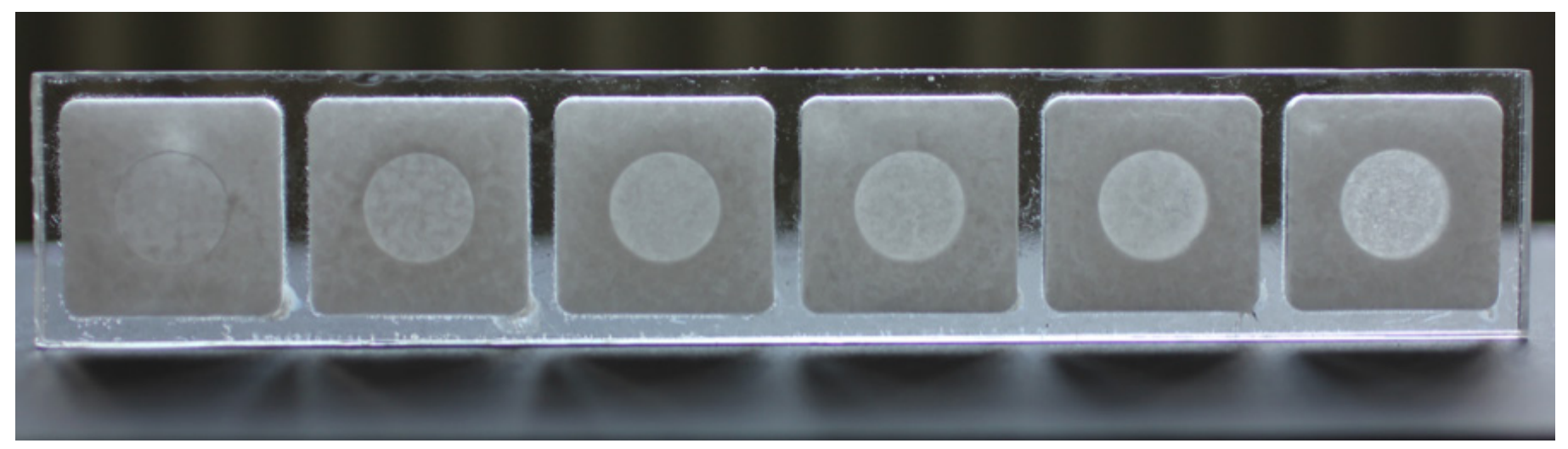


schools, is generally more than $50 \%$ via the grant funding mechanism. There is also a significant difference in terms of money allocation and deliverables. The gift mechanism is a riskier prospect as the giver of the gift has far less control over the use of the monies donated. There is no formal contract within the gift mechanism and no deliverables are specified.

\section{PROJECT EXAMPLE 2: SOLAR PETALS}

Solar Petals is a project initiated by architectural firm Arquitectonica through a grant funding mechanism to the university. The grant mechanism allowed the architecture firm to have greater contractual control over the project time line and deliverables. The partnership was initiated to add practice-based research to the architectural office and bring practical experience to students. This exploratory project sought to advance the architectural application shape-memory materials. The responsive petal array translates changes in sunlight levels to the interactive façade and communicates environmental fluctuation to building occupants. Solar Petals is a demonstration project is a step toward making architecture more adaptive to environmental change and to communicate this relationship to the public (Figure 4.)

\section{PROJECT BACKGROUND}

Designed for a new retail and housing tower complex in Miami, FL, Solar Petals is an interactive system that is responsive to sunlight and serves as an indicator of solar insolation available for powering the building complex. The technology bridges photovoltaic energy harvesting, sensing technologies, programming and shape memory alloy actuation. Project complexity required expertise from a collaborative team of students from architecture, electrical engineering, interaction design, the arts and computer science. The design/ build process was the common language amongst the architectural office and the diverse student group. The team worked at 1:1 scale throughout the project and feedback from the prototypes catalyzed idea development and team-based decision-making. In this process, the act of making served as both a metric of proof and a method of creative inquiry. The scale of the models remained consistent, but the materials, actuating systems and phenomenal qualities increased in specificity and resolution. Full-scale working prototypes were used to communicate design possibilities and served as medium for the architecture firm to be directly involved in the design process.

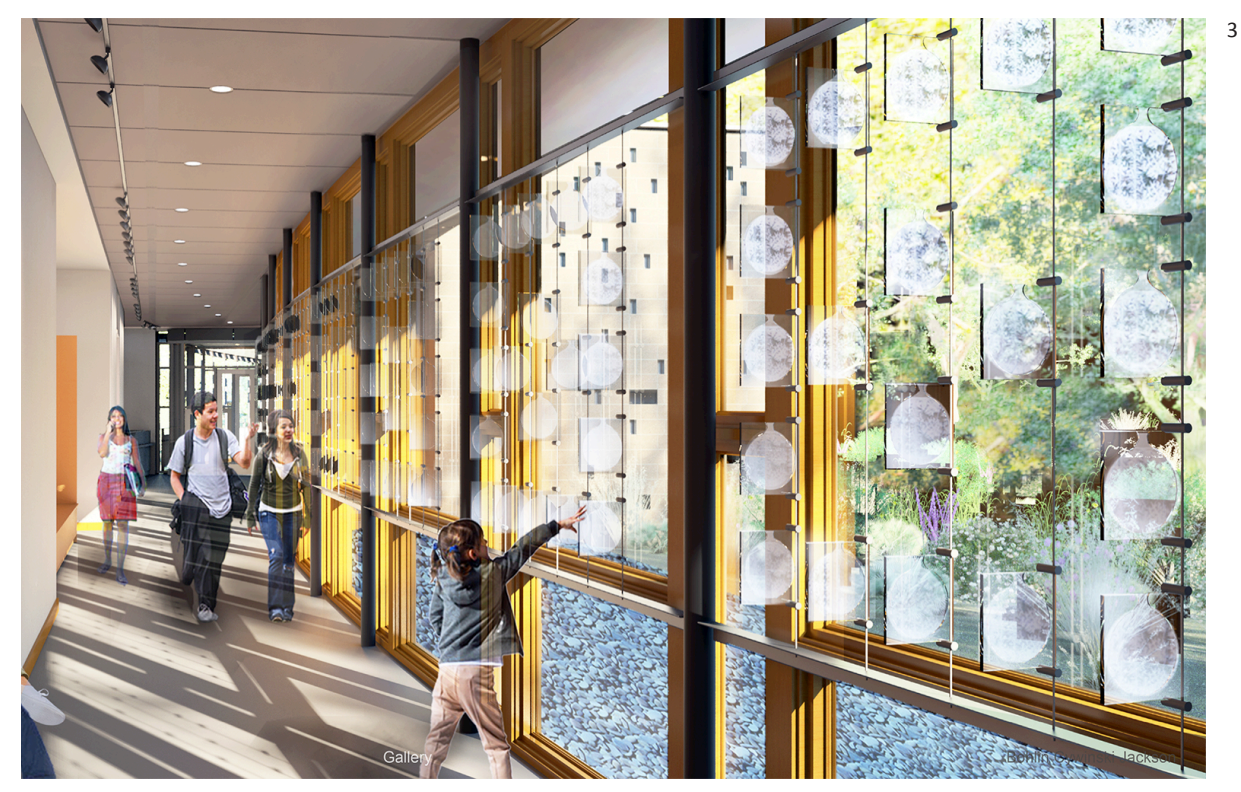

Figure 3: Interactive installation of PCM tiles (Frick Environmental Center). 
Figure 4: Drawings of solar petal showing onboard photovoltaics that charge a capacitor to trigger the shape memory alloy(upper row) The first image illustrates the petal in the relaxed state, the second image illustrates the petal under charge. Prototype of solar petal array (lower row)
Designed as an array of 900 petals, the array demonstrates the experiential potential of the relationship of environmental fluctuation and physical computation. Actuated by shape memory alloys, the petal array serves as an interactive facade that visually communicates the availability of incoming solar radiation to power the building to occupants.

\section{HOW DOES PRACTICE BENEFIT FROM ACADEMIC PARTNERSHIP?}

Practice benefits from university partnerships by gaining access to expertise and technology that is not currently housed within the office. Often this includes tapping into faculty and student ability, multidisciplinary contacts, and prototyping facilities. Academic coursework is somewhat resistant to economic pressures, allowing faculty and student teams to run through variations of an idea without direct monetary pressure. Academic teams are able to engage less constrained "wicked problems" ${ }^{2}$ where the variables are fluid. The academic environment is also highly reflective and advocates critical evaluation to advance a design prospect. In partnership with practice, academia can effectively train students for emerging positions within practice that did not exist a decade ago. These positions require technical acuity, creative synthesis, and systems thinking skills.

In the cases of collaboration with Bohlin Cywinski Jackson Architects and Arquitectonica, collaboration generated knowledge exchange that included experience with responsive materials and designing innovative ways to visually demonstrate the qualitative aspects of sustainable technologies to building occupants.

\section{HOW DOES THE UNIVERSITY BENEFIT?}

Faculty and students benefit from external funding streams, the ability to work on advanced projects, and by gaining knowledge and feedback from practitioners. Practitioners provide insight into current issues of practice and enable curricula to respond to the variable landscape of practice with more acuity. Knowledge exchange from practice is critical to academia as the definition of an architect is continually being redefined. Past curricula focused on a set of relatively finite skills that would be useful throughout an architects career. More recently, there is an emergent curricula shift to focus on skills and
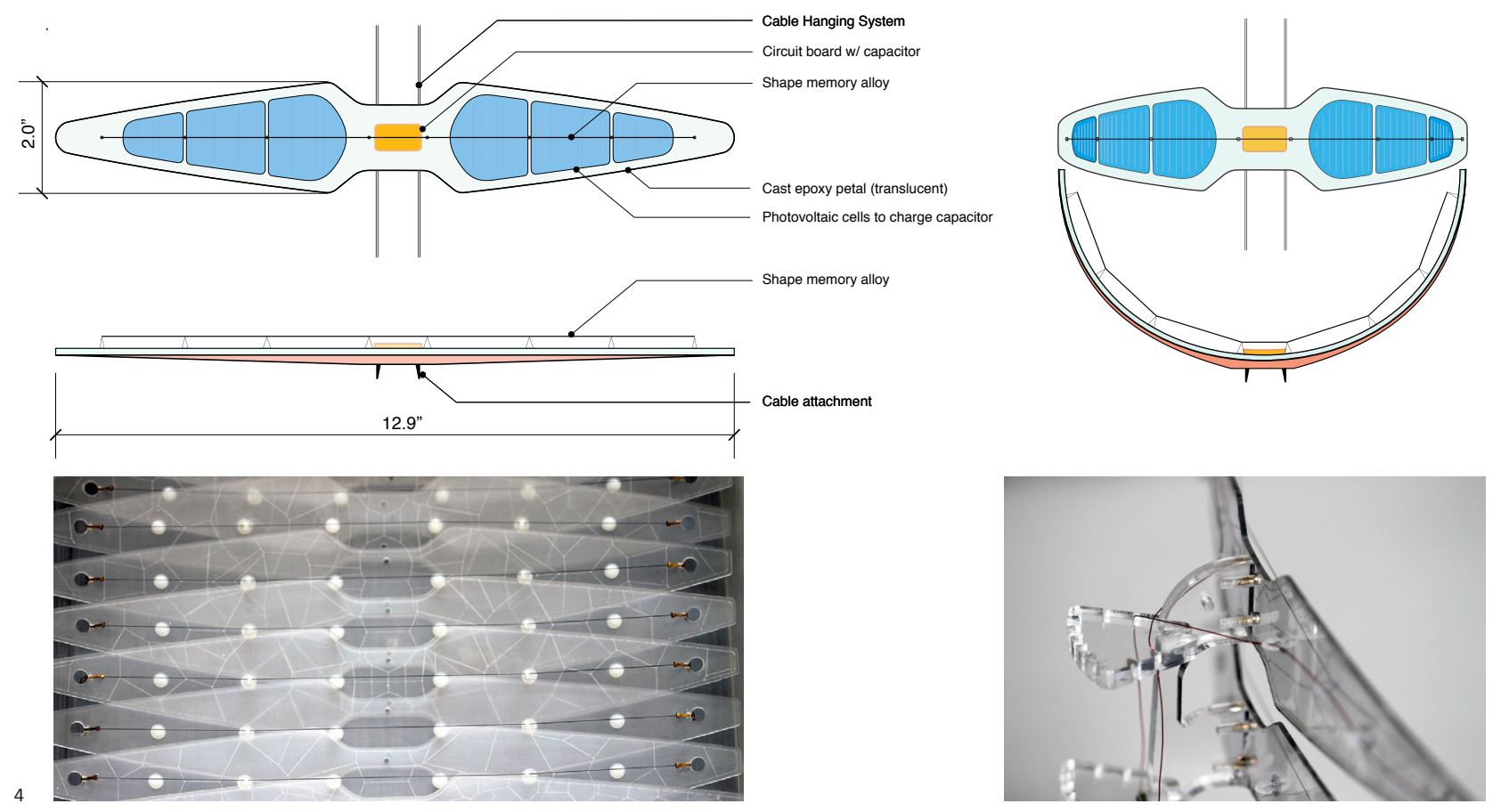
competencies while recognizing the pace of change in practice, and curricula is responding by shifting toward models that teach students to apply knowledge in novel situations. Educators train architects for an unpredictable future in terms of the boundaries of the definition of 'architect.' This redefinition becomes clear to instructors when student teams interact with design professionals to generate new knowledge through design.

\section{PATHS FORWARD}

KieranTImberlake, SOM and Perkins + Will are examples of small and large firms that make research explicit in their philosophical and pragmatic approach to design. These firms are among an emergent stream of firms that house internal research and development organizations that expand the range and depth of projects the firms are able to obtain. These firms are advocating a more porous boundary between design research and practice. As the spectrum of building technology broadens and the complexity of the design process increases, academic entities are poised to collaborate with private entities to train students for research and development positions that will add value to practice.

\section{BACKGROUND NOTES}

Phase change materials (PCMs) applicable to building technology include salts, paraffin and organic fatty acids. They have the potential to offset heating and cooling loads by serving as high mass thermal energy storage. Compared to concrete PCMs are far more effective at thermal storage during phase transition. Thermal mass has long been used to stabilize temperature in buildings and developed into a standardized technology by Edward Morse who patented the 'Trombe' wall system in $1881 .{ }^{3}$ PCMs are a more recent advancement of this system, dating to the 1970s, and are effective due to the high heat of fusion generated when a material changes states. Today, PCMs are most commonly encapsulated in plaster then applied as an interior surface or encapsulated in plastic sheeting then applied behind drywall.

Shape memory alloys exhibit shape change characteristics in response to temperature change. The alloys used in this project are a composite of nickel and titanium and contract $5 \%$ of their length and serves as a non-mechanical actuator for the petals. 